\title{
O DIREITO CONSTITUCIONAL À SAÚDE NO BRASIL
}

\section{THE CONSTITUTIONAL RIGHT TO HEALTH IN BRAZIL}

\author{
Felipe Ribeiro Lemos \\ Especialista em Gestão Pública - UEMG \\ E-mail: felipelemos@yahoo.com.br \\ Alexandre Santiago Teixeira \\ Especialista em Gestão Pública - UEMG \\ E-mail: alexandre.veterinario18@gmail.com \\ João Gabriel Fassbender Barreto Prates \\ Mestre em Direito - Faculdades Milton Campos \\ E-mail: joaogabrielprates@hotmail.com
}

Recebido: 09/06/2021 - Aceito: 11/06/2021

\section{RESUMO}

O Sistema Único de Saúde (SUS), implantado no Brasil após a promulgação da Constituição de 1988, foi um marco nas políticas públicas de saúde, garantindo a milhões de pessoas o acesso gratuito e universal. Entretanto, ao passo em que o sistema expandia, também cresciam as judicializações e com isso novas interpretações sobre 0 alcance das propostas e da responsabilização dos agentes públicos.

Palavras-chave: Constituição de 1988; Direito à saúde; Judicialização da saúde; Responsabilidade social; Sistema Único de Saúde.

\section{ABSTRACT}

The Unified Health System (SUS), implemented in Brazil after the promulgation of the 1988 Constitution, was a milestone in public health policies, guaranteeing millions of people free and universal access. However, as the system expanded, so did the judicialization and, with it, new interpretations about the scope of the proposals and the accountability of public agents.

Keywords: Constitution of 1988. Right to health. Judicialization of health. Social responsability. Health Unic System. 


\section{INTRODUÇÃO}

O direito à saúde foi uma conquista histórica da sociedade brasileira, consubstanciada na positivação constitucional de tal garantia. Todavia, ao longo desses quase 30 anos de vigência, o texto da Constituição Federal ainda é alvo de muitos debates doutrinários e judiciais. Além disso, o SUS, tem sido objeto de ataque e desestabilização, principalmente por parte de setores interessados em enfraquecer a assistência gratuita à saúde.

Isto posto, pretende-se com a presente pesquisa, compreender a participação e o alcance do controle da sociedade civil na construção de políticas públicas de saúde, bem como avaliar como a judicialização e as desigualdades sociais afetam esse importante direito no país.

\section{DIREITO À SAÚDE NA CONSTITUIÇÃO DE 1988}

De início, é importante fazer alguns apontamentos a respeito dos direitos sociais no ordenamento jurídico brasileiro, em especial da elevação ao status constitucional da proteção de muitos deles. Ainda, este capítulo cuida de apresentar algumas questões pertinentes à garantia dos direitos sociais pelo Estado brasileiro, notadamente algumas discussões sobre a possibilidade de se efetivar os mandamentos constitucionais.

Neste sentido, cumpre indicar que os direitos sociais constam de forma expressa no Capítulo II - Dos Direitos Sociais, iniciando-se no artigo 6ำ da Constituição, com a seguinte redação:

CAPÍTULO II

DOS DIREITOS SOCIAIS

Art. 6으o São direitos sociais a educação, a saúde, a alimentação, o trabalho, a moradia, o transporte, o lazer, a segurança, a previdência social, a proteção à maternidade e à infância, a assistência aos desamparados, na forma desta Constituição.

Portanto, a Carta Magna que garante a existência do Estado Democrático de Direito no Brasil tratou de considerar estes direitos passíveis de proteção constitucional, de modo a alça-los à posição de prevalência e prioridade, em especial quando da formulação de políticas públicas. 


\section{Revista Multidisciplinar do Nordeste Mineiro, v.2 2021/02 \\ ISSN 2178-6925}

De tal modo, cabe complementar a indicação legislativa acerca do direito à saúde, que está marcado no texto constitucional, a partir do art. 196:

\section{Seção II \\ DA SAÚDE}

Art. 196. A saúde é direito de todos e dever do Estado, garantido mediante políticas sociais e econômicas que visem à redução do risco de doença e de outros agravos e ao acesso universal e igualitário às ações e serviços para sua promoção, proteção e recuperação (...).

Através da transcrição do texto constitucional, surge o primeiro foco de divergência no que concerne à garantia dos direitos: como viabilizar o direito à saúde e, no limite, os direitos sociais aos cidadãos, no bojo de um sistema econômico fundado sobre a lógica da escassez de recursos? Não obstante, outra dúvida: pode o Estado, em algum momento, se negar a prestação, afastando a incidência expressa da Constituição que, em última análise, é a "criadora" de toda a ordem jurídica vigente?

Os dramas supra expostos são reduzidos, na doutrina, ao seguinte embate conceitual: Mínimo existencial x Reserva do possível.

Para fins didáticos, é importante conceituar cada um destes elementos e, em seguida, conduzir algumas conclusões.

\subsection{Mínimo Existencial}

Como toda narrativa é orientada por visões de mundo e preferências, é fundamental fixar a ordem de valores que neste trabalho se defende. Explica-se: para se discutir o acesso aos direitos sociais pela população, é preciso fixar em primeiro lugar onde está a população, o povo, em detrimento de análises que preterem os interesses populares, em função de outros tantos. Assim, inicia-se pelo estudo do conceito de mínimo existencial, ínsito a todo indivíduo para, a seguir, apresentar as características do que se nomeou "reserva do possível".

Resultante da conjugação da dignidade da pessoa humana, da liberdade material e do Estado Social, esta expressão surgiu na Alemanha, em uma decisão do Tribunal Federal Administrativo proferida em 1953, sendo posteriormente incorporada na jurisprudência do Tribunal Federal Constitucional daquele país. (NOVELINO, 2014, p. 595). 
As interpretações jurídicas sobre a aplicação e, mais, a garantia dos direitos sociais alcançou o conceito de mínimo existencial exatamente para marcar posição quanto à exigência que há, sobre o Estado, de que este possa assegurar condições mínimas de vida para cada um de seus "súditos".

No caso da Constituição brasileira, consta dali um princípio implícito, comumente designado de princípio da dignidade humana. É desse princípio que decorre a teoria do mínimo existencial.

Vale-se de doutrina especializada para elucidar a questão:

\begin{abstract}
O mínimo existencial consiste em um grupo menor e mais preciso de direitos sociais formado pelos bens e utilidades básicas imprescindíveis a uma vida humana digna. Na concepção de Ana Paula de BARCELLOS (2002, p. 245-47), engloba os direitos à saúde, educação, assistência aos desamparados (alimentação, vestuário e abrigo) e acesso à justiça. Para a autora, na formulação e execução das políticas públicas, o mínimo existencial deve nortear o estabelecimento das metas prioritárias do orçamento. Somente após serem disponibilizados os recursos necessários a sua promoção, deve-se discutir, em relação ao remanescente, quais serão as demandas a merecer atendimento. (NOVELINO, 2014, p. 595).
\end{abstract}

Não resta dúvida que é um dever do Estado assegurar que todos os indivíduos possam fruir de uma vida com dignidade para que, a partir daí, possa se desenvolver e ajudar na construção da nação. Não se concebe o progresso social e econômico em um Estado em que milhões de pessoas não têm acesso a serviços básicos e, justamente por isso, não gozam de vida digna e justa, perecendo sob a fome e a miséria.

\title{
2.2. Reserva do possível
}

Em contrapartida, no outro prato da balança verifica-se o argumento de que, em razão da escassez de recursos, própria de um sistema capitalista, por vezes o Estado não tem condições financeiras de arcar com as prestações que deveria, no caso aqui tratado, a concretização dos direitos sociais previstos na Constituição.

Como se percebe, essa é a maior arma de defesa das administrações Brasil afora. Ou seja: os executivos municipais, estaduais e federais geralmente 
lançam mão da reserva do possível para justificar eventual ausência de prestação social correspondente.

Todavia, é bom frisar que isso não pode servir de salvaguarda dos entes estatais, acobertando inércia e má construção de políticas públicas. Não se pode utilizar deste conceito para se abster de concretizar direitos sociais.

De acordo com PAULO e ALEXANDRINO (2012): "É importante entender que esse princípio não significa em 'salvo conduto' para o Estado deixar de cumprir suas obrigações sob uma alegação genérica de quem "não existem recursos suficientes".

Enfim, o dilema que aqui existe pode ser resumido no conceito de "escolhas trágicas", donde se extrai a necessidade de o poder público avaliar todos os atores envolvidos na prestação de um serviço público ou, antes, na elaboração de uma política pública. A "tragédia" da escolha se dá exatamente em razão da contraposição de duas importantes contingências: de um lado, a imposição constitucional que obriga a prestação do serviço, a garantia do acesso aos direitos sociais básicos, aptos a proporcionar uma vida minimamente digna a cada brasileiro; de outro, há a escassez de recursos financeiros com a qual o ente público lida diariamente, erigindo-se obstáculos para o financiamento da saúde e da assistência pública.

\section{DECISÕES JUDICIAIS SOBRE ACESSO À SAÚDE}

Há muitas críticas quanto à participação do judiciário como ator principal da implementação dos direitos sociais. Essa discussão orbita na questão da separação dos poderes e, sobretudo, quanto ao papel dos poderes legislativo e executivo como titulares soberanos de legitimidade e, mais que isso, instâncias responsáveis pela elaboração e efetivação de políticas públicas que concretizem os direitos sociais. Ainda, há um argumento sobre a suposta inércia que surgiria no âmbito destes organismos aqui apontados, com um judiciário amplamente garantidor e o real realizador dos direitos sociais, no lugar dos poderes legalmente habilitado para tanto. 


\section{Revista Multidisciplinar do Nordeste Mineiro, v.2 2021/02 \\ ISSN 2178-6925}

Em razão da escassez de recursos orçamentários, alega-se que a escolha sobre quais direitos merecem ser priorizados deveria recair exclusivamente sobre os representantes do povo eleitos para tal fim. (NOVELINO, 2014, p. 592).

Noutro giro, há parte da doutrina que vê na atuação do judiciário a única e mais imediata salvaguarda dos direitos sociais, especialmente nos casos de omissão deliberada das instancias constitucionalmente incumbidas de fazê-lo, quais sejam, os poderes executivo e legislativo.

Do ponto de vista constitucional, negar a possibilidade de intervenção judicial colidiria frontalmente com o art. 5ํ, XXV, da CF.

Ainda sob a ótica da representatividade, a ação do judiciário se impõe:

No Brasil, o déficit democrático das instituições representativas e a constatação de omissões deliberadas por parte do legislador têm contribuído decisivamente para a adoção de uma postura mais atuante do Poder Judiciário na implementação dos direitos sociais. (NOVELINO, 2014, p. 592)

É importante destacar que não é objetivo deste trabalho esmiuçar a intervenção do poder judiciário na garantia de direitos sociais, tampouco aprofundar na pertinência ou não de tal intromissão. Todavia, serão indicadas duas decisões que ilustram bem o cenário atualmente vivido no país, qual seja, o de um judiciário garantidor de prestações sociais, cumprindo função que, em tese, seria reservada a outros poderes da república.

Primeiro, um julgado do STF, de relatoria do Ministro Celso de Melo, que garante o fornecimento gratuito de medicamentos a um paciente portador de AIDS. Nas palavras dos Profs. Vicente Paulo e Marcelo Alexandrino (2012, p. 255):

(...) O Supremo Tribunal Federal reconheceu a um paciente portador do vírus HIV/AIDS o direito à distribuição gratuita de medicamentos, firmando entendimento de que tal medida - distribuição gratuita de medicamentos a pessoas carentes - é dever constitucional do Poder Público, a fim de dar efetividade a preceitos fundamentais da Constituição da República (arts. 50, caput e 196).

Desse modo, decidiu a Suprema Corte na direção de fornecer, sem custos, os medicamentos necessários para a sobrevivência do paciente, sob a tese de que 
não se pode vetar o acesso à saúde àqueles que não gozam de condições financeiras para bancá-la, sob o risco de se afastar o texto constitucional.

Portanto, a corte máxima vem atuando, desde há muito, como última trincheira do cidadão, na busca pela garantia de medicamentos. Mas não é só.

O STF, além de proferir decisões que obrigam o fornecimento gratuito de medicamentos, ele também constrange, jurídica e financeiramente, o órgão estatal a fazê-lo. Isso porque também é ventilada as hipóteses, em muitos casos, de bloqueio de valores, junto às finanças públicas, para garantir que a decisão proferida seja cumprida.

Assim relatam PAULO; ALEXANDRINO (2012, p. 255):

A verdade é que o STF confere tamanha relevância ao desiderato constitucional de tornar efetivos os direitos sociais fundamentais que, em inúmeros casos, tem determinado até mesmo o bloqueio de verbas públicas do ente federado, em favor de pessoas hipossuficientes, a fim de Ihes assegurar o fornecimento gratuito de medicamentos, como corolários dos direitos à saúde e à vida.

Ou seja: não bastasse o judiciário interferir na prestação de serviços públicos, ele ainda determina que fatia do orçamento seja destinado para tal. Para muitos, essa intromissão seria descabida e violaria o famigerado princípio da repartição de poderes. Entretanto, vive-se no país uma inércia gerencial muito grande, o que requer uma posição do judiciário, pois na situação atual, a população ficaria refém de serviços públicos mal prestados que, no limite, causam doença e morte naqueles que não conseguem arcar com acesso à saúde privada.

Em recente decisão, o Min. Celso de Melo reafirmou este entendimento, já consolidado na corte, no julgamento do ARE $949341 \mathrm{AgR} / \mathrm{SP}$ :

\footnotetext{
EMENTA: RECURSO EXTRAORDINÁRIO COM AGRAVO - FORNECIMENTO DE MEDICAMENTOS - BLOQUEIO DE VERBAS PÚBLICAS - POSSIBILIDADE REPERCUSSÃO GERAL DA MATÉRIA QUE O PLENÁRIO DO STF RECONHECEU NO JULGAMENTO DO RE 607.582-RG/RS, REL. MIN. ELLEN GRACIE - REAFIRMAÇÃO, QUANDO DA APRECIAÇÃO DE MENCIONADO RECURSO, DA JURISPRUDÊNCIA QUE O STF FIRMOU NO EXAME DESSA CONTROVÉRSIA - RECURSO DE AGRAVO IMPROVIDO. (ARE $949341 \mathrm{AgR}$, Relator(a): Min. CELSO DE MELLO, Segunda Turma, julgado em 21/06/2016, ACÓRDÃO ELETRÔNICO DJe-137 DIVULG 30/06/16 PUBLIC 01/07/16)
}

É neste cenário, portanto, que se faz necessário examinar a questão da participação social na elaboração de políticas de saúde, visto que os mandamentos 
constitucionais são reiteradamente descumpridos pelos gestores públicos, carecendo de intervenção judicial para fazê-los cumprir.

\section{A CONSOLIDAÇÃO DO SISTEMA ÚNICO DE SAÚDE}

Nesta etapa da pesquisa, pretende-se apresentar uma visão geral sobre o Sistema Único de Saúde, experiência única no planeta, que congrega uma série de inciativas e coberturas de saúde à população brasileira.

Assim, aponta-se alguns conceitos para entender do que trata o SUS, como atua e quais os princípios que orientam a prestação de seus serviços.

\subsection{O conceito de saúde}

O dicionário "Michaelis" define saúde como: "estado do organismo com funções fisiológicas regulares e com características estruturais normais e estáveis, levando-se em consideração a forma de vida e a fase do ciclo vital de cada ser ou indivíduo".

Embora como descrito acima, a saúde esteja vinculada a questões físicas e fisiológicas do indivíduo, são diversos os fatores que a determinam e condicionam, tais como: moradia, saneamento básico, alimentação, transporte, lazer, entre outros bens e serviços que são essenciais para a vida das pessoas. É neste cenário que a administração pública deve se debruçar, afinal, a saúde é mais ampla do que se conceitua.

\subsection{0 surgimento do SUS}

A Constituição Federal de 1988 é reconhecida como uma das mais avançadas do mundo, com uma abordagem dentro do ordenamento jurídico na qual o ser humano é colocado como o pilar da existência do Estado, cabendo a este a garantia de direitos elementares, como a saúde.

Tendo como base o princípio estabelecido na Constituição, em seu artigo 196, a saúde se apresenta como um direito universal de todos os cidadãos 
naturais, naturalizados ou residentes no país, sendo, portanto, um dever do Estado garantir políticas que garantam o pleno atendimento de maneira universal e igualitária.

Não obstante os dispositivos constitucionais, ainda se fez necessário a regulamentação de um sistema universal de saúde. Foi nesse momento que surgiu o SUS, por meio da lei nำ8.080, de 19 de setembro de 1990.

Assim versa 0 art. $4^{\circ}$ da lei supracitada:

O conjunto de ações e serviços de saúde, prestados por órgãos e instituições públicas federais, estaduais e municipais, da Administração direta e indireta e das fundações mantidas pelo Poder Público, constitui o Sistema Único de Saúde (SUS).

Desta forma o SUS é concebido com o objetivo de ser uma rede composta pelos entes da federação, através da administração direta e indireta, bem como das fundações mantidas por estes, afim de garantir o direito constitucional. Por ouro lado, a lei também assegura a presença da iniciativa privada, que por sua vez deverá ter um caráter complementar as ações estatais.

\subsection{Os princípios do SUS}

Um dos pontos mais importantes do SUS é o conceito ampliado de saúde, que veio após um amplo debate da sociedade com a classe política.

É importante mencionar que a Constituição, bem como a lei do SUS surgem após um período intenso governado por um regime militar. A ideia de cidadania e de luta por garantias individuais e coletivas estavam muito evidentes no seio dos movimentos populares.

Com este novo cenário também foi possível conceber o quadro de enormes desigualdades existentes entre os mais ricos e os mais pobres. Foi necessário, assim, a busca de mecanismos que pudessem deixar igualitárias estas discrepâncias e garantir o acesso a todos os cidadãos aos elementos básicos para sobrevivência e dignidade.

Para lidar como esta nova conjuntura foi necessária a transformação do conceito de saúde, dos serviços prestados e das relações com a sociedade. Assim, 


\title{
Revista Multidisciplinar do Nordeste Mineiro, v.2 2021/02 \\ ISSN 2178-6925
}

de um lado era primordial formar e qualificar profissionais, garantir medicamentos e construir novas unidades de atendimento. De outro, a necessidade urgente de projetos que fizessem com que as medidas planejadas pelo Estado chegassem a cada canto e recanto deste país.

\subsubsection{Universalidade}

A universalidade é um conceito estabelecido pela Constituição, conforme descrito no art. 196: "A saúde é direito de todos e dever do Estado". Nesta ceara o acesso aos serviços de saúde é garantido a todos os indivíduos, independentes de suas características sociais ou pessoais.

\subsubsection{Equidade}

A equidade tem como finalidade a diminuição das desigualdades, sendo, deste modo, a representação da justiça social que irá garantir ao indivíduo a assistência à saúde, desprendidos de qualquer espirito de preconceito e privilégios. O SUS deve estar atento as reais necessidades da população e ser atendida da melhor maneira possível.

\begin{abstract}
Equidade é tratar desigualmente os desiguais, pois cada um tem uma necessidade diferente. Tratar cada caso como um caso e privilegiar as pessoas que estão necessitando de mais atendimento, de mais atenção, não necessariamente de consulta. (...) É um atendimento de quem precisa consumir mais e de quem precisa consumir menos. Respeitando a individualidade de cada um, oferecer aquilo que a pessoa necessita. É poder olhar para o paciente e deixá-lo falar, dar acesso a ele e tratar daquilo que ele realmente precisa, dando respostas conforme essa necessidade. (GRANJAA et. al., 2010).
\end{abstract}

Cabe ressaltar que embora todos os indivíduos tenham direitos iguais, as suas necessidades são diferentes. Por isso o princípio da equidade busca garantir a igualdade de condições de pleno acesso aos diversos níveis de complexidade do sistema de saúde.

\subsubsection{Integralidade}


O princípio da integralidade estabelece que o Estado deve ser o garantidor da promoção, proteção e reabilitação da saúde do indivíduo, garantindo serviços de qualidade e a plena recuperação do paciente.

Tendo como base que o ser humano é indivisível e componente de uma sociedade, o mesmo se espera do Estado para como o indivíduo. O seu direito não pode ser fracionado, mas sim integral. Ao mesmo tempo, tal princípio assegura a existência e fortalecimento continuo de políticas públicas que assegurem nas mais diversas áreas o pleno atendimento e acesso do cidadão a saúde.

\subsubsection{Gratuidade}

A gratuidade sempre foi um tema polêmico e bastante discutido nos diversos fóruns sobre a saúde. Tal princípio pressupõem a ausência de custos aos usuários no exercício de seu direito assegurado constitucionalmente. É óbvio que tal medida não impede que a população venha a contribuir com o SUS, através dos inúmeros impostos e taxas estabelecidas pelo poder público.

$\mathrm{O}$ art. 65 do Código de Ética Médica prevê que é vedado ao médico: "Cobrar honorários de paciente assistido em instituição que se destina à prestação de serviços públicos, ou receber remuneração de paciente como complemento de salário ou de honorários”.

É importante notar que o princípio da gratuidade, estabelecido pelo SUS, dá uma conotação de compromisso do Estado com os cidadãos e configura como um importante direito a ser preservado.

\subsection{Os objetivos do SUS}

Com base na Lei Orgânica da Saúde, em seu art. 5ำ I, os objetivos do SUS são assim identificados:

I - a identificação e divulgação dos fatores condicionantes e determinantes da saúde; II - a formulação de política de saúde destinada a promover, nos campos econômico e social, a observância do disposto no $\S 1^{\circ}$ do art. $2^{\circ}$ desta lei; III - a assistência às pessoas por intermédio de ações de promoção, proteção e recuperação da saúde, com a realização integrada das ações assistenciais e das atividades preventivas. 
Seguindo os pressupostos da referida lei é objetivo do SUS garantir condições de atuação das equipes de prevenção na redução dos riscos de doenças e epidemias. É previsto também que o Estado identifique e promova políticas públicas tendo como meta o aperfeiçoamento do sistema e o aumento do alcance de tais medidas, garantindo o acesso de todos a condições básicas de saúde. É nesta proposta que o direito a saúde se constitui como universal e gratuito.

\section{POR QUE AS DESIGUALDADES SOCIAIS AFETAM A SAÚDE?}

São muitos os fatores que influenciam na oferta e no consumo dos serviços de saúde, quais sejam: a disponibilidade, o tipo, a quantidade de serviços e recursos (financeiros, humanos, tecnológicos), a localização geográfica, a cultura médica local, a ideologia do prestador, e mesmo as escolhas de cada indivíduo que tomará o serviço.

Muitos também são os elementos promotores de sofrimento relacionados à pobreza e as desigualdades, tais como o desemprego, o analfabetismo, a violência, as precárias condições de saneamento básico, a dificuldade de acesso à saúde, a desnutrição e a doença. Tudo isso, acaba por perpetuar uma cultura de exclusão social e a sensação de ausência do Estado na vida das pessoas.

O reflexo imediato é que os piores índices de saúde se encontram entre os grupos populacionais mais vulneráveis, indicando que a posição do indivíduo na estrutura social é importante condicionante de necessidades em saúde, sendo que o risco de agravos tende a ser maior para aqueles indivíduos pertencentes aos grupos sociais menos privilegiados.

Muitos são os dados do Ministério da Saúde que atestam para a realidade de como as desigualdades regionais, econômicas, étnicas e de gênero, afetam, sobremaneira, a vida e a saúde da população brasileira. As maiores taxas de mortalidade infantil podem ser observadas entres os grupos sociais menos abastados e a população indígena, principalmente pela desnutrição. As populações de etnia negra apresentam maiores riscos de morte, por doenças infecto-parasitárias, problemas puerperais e violência. A diferença de IDH entre negros e brancos chega a ser $16 \%$, sendo a educação a dimensão responsável 
pela maior diferença. O Nordeste é a região com menor expectativa de vida, cinco anos a menos do que na região Sul. Adolescentes são mães antes dos 14 anos, com maior frequência entre meninas negras, residentes em municípios com até 100 mil habitantes e com alto índice de pobreza, em especial os localizados nas Regiões Norte e Centro-Oeste (BRASIL, 2008).

Percebe-se com efeito que as desigualdades se manifestam no espaço geográfico do país, expondo a história social, econômica e cultural de cada região, estado ou município. Nos grupos sociais mais vulneráveis como as populações rurais, negros e índios, as desigualdades refletem a exclusão histórica desses grupos, existente até hoje.

Embora a noção de equidade seja utilizada indistintamente, por políticas voltadas à saúde, pressupondo redistribuição desigual de recursos, por causa dos ajustes que devem ser efetuados em função das desigualdades existentes. A questão da equidade em tem sido objeto de intenso debate nas últimas décadas, e as dificuldades encontradas para a sua aplicação resultam também do insuficiente desempenho. Algumas das questões referentes a esta temática são recorrentes, como as derivadas das relações entre condições socioeconômicas e saúde, bem como aquelas voltadas à articulação entre desigualdade em saúde e desigualdade no acesso a bens e serviços.

Faz-se necessário também distinguir equidade em saúde de equidade no uso ou no consumo de serviços de saúde, porque os determinantes das desigualdades no adoecer e no morrer diferem daqueles das desigualdades no consumo de serviços de saúde. As desigualdades em saúde refletem, dominantemente, as desigualdades sociais e, em função da relativa efetividade das ações de saúde, a igualdade no uso de serviços de saúde é condição importante, porém, não suficiente para diminuir estas desigualdades.

A ética aristotélica, dentro do contexto político, se apoia, sobretudo, numa moral de caráter virtuoso, na busca da felicidade humana, que tem como objetivo precípuo o estabelecimento do que é, efetivamente, o bem supremo. Portanto os problemas resultantes das desigualdades sociais tão presentes no cotidiano brasileiro, afetam não somente os menos favorecidos, mas toda a sociedade. 


\section{CONCLUSÃO}

Ao final deste estudo sobre a saúde pública no Brasil, foi possível alcançar algumas conclusões que reflexem o cenário brasileiro:

a) O SUS é uma experiência fundamental para o Estado brasileiro, pois garante a prestação do direito à saúde à população mais carente do país;

b) A conformação atual do modelo federativo brasileiro, aliada à ausência de políticas públicas estruturantes, força a atuação do judiciário, como garantidor do acesso à saúde;

c) A judicialização nada mais é que o preenchimento do espaço deixado pela falta de vontade política e, é bom que se diga, de gestores públicos comprometidos com a causa da saúde pública e gratuita;

d) Diante deste cenário, a população passa a se organizar em associações, na tentativa de promover o acesso à saúde e desonerar os municípios de sua responsabilidade. Apesar de não ser o ideal, a situação ameniza a espera de milhares de pessoas que padecem sem tratamento adequado e necessário;

e) As Conferências de Saúde são de extrema relevância para aproximar os cidadãos dos poderes executivo e legislativo, colaborando assim para humanizar as decisões políticas.

\section{REFERÊNCIAS}

BARCELLOS, Ana Paula de. A eficácia jurídica dos princípios constitucionais. Rio de Janeiro: Renovar, 2011.

BARCELLOS, Ana Paula de. Comentários aos artigos 196 a 200 da Constituição Federal de 1988. In: BONAVIDES, Paulo; MIRANDA, Jorge; AGRA, Walber de Moura. Comentários à constituição federal de 1988. Rio de Janeiro: Forense, 2009. 
BRASIL. Constituição (1988). Constituição da República Federativa do Brasil. Disponível em: http://www.planalto.gov.br/ccivil_03/constituicao/constituicao.htm. Acessado em: 04 jul. 2018.

BRASIL. Lei n 8.080, de 19 de setembro de 1990. Dispõe sobre as condições para a promoção, proteção e recuperação da saúde, a organização e o funcionamento dos serviços correspondentes e dá outras providências. Disponível em: http://www.planalto.gov.br/ccivil_03/leis/L8080.htm. Acessado em: 04 jul. 2018.

BRASIL. Ministério da Saúde. ABC DO SUS: doutrinas e princípios. Disponível em: http://www.pbh.gov.br/smsa/bibliografia/abc_do_sus_doutrinas_e_principios.pdf. Acessado em: 05 jul. 2017.

BRASIL. Ministério da Saúde. Os novos desafios da saúde no Brasil. Disponível em: https://www.gov.br/saude/pt-br. Acessado em: 01 jul. 2008.

BRASIL. Supremo Tribunal Federal. Jurisprudências do Tribunal. Disponível em: http://portal.stf.jus.br/. Acessado em: 05 jul 2018.

Conselho Federal de Medicina. Código de Ética Médica. Disponível em: http://www.rcem.cfm.org.br/index.php/cem-atual. Acessado em: 05 jul. 2018.

GRANJAA, Gabriela Ferreira; ZOBOLIB, Elma Campos Pavone; FORTESC, Paulo Antônio de Carvalho. Equidade no sistema de saúde brasileiro: uma teoria fundamentada em dados. São Paulo, v.34, n.1, jan./mar. 2010.

LENZA, Pedro. Direito Constitucional esquematizado. 15. ed. ver, atual. e ampl. São Paulo: Saraiva, 2011. 
Revista Multidisciplinar do Nordeste Mineiro, v.2

MAGALHÃES, R. Enfrentando a pobreza, reconstruindo vínculos sociais: as lições da Ação da Cidadania contra a Fome, a Miséria e pela Vida. Cad. Saúde Pública, 2002.

MICHAELIS. Moderno Dicionário da Língua Portuguesa. Disponível em: http://michaelis.uol.com.br/moderno-portugues/. Acessado em: 04 jul. 2018.

NOVELINO, Marcelo. Manual de direito constitucional. 9. ed. rev. e atual. Rio de Janeiro: Forense; São Paulo: MÉTODO, 2014.

PAULO, Vicente. ALEXANDRINO, Marcelo. Direito Constitucional descomplicado. 14.ed. Rio de Janeiro: MÉTODO, 2015. 